\title{
Seasonality in UV-absorbing compounds of cyanobacterial mat communities from an intertidal mangrove flat
}

\author{
Ulf Karsten ${ }^{1, *}$, Josef Maier ${ }^{2}$, Ferran Garcia-Pichel ${ }^{3}$ \\ 'Alfred Wegener Institute for Polar and Marine Research, Am Handelshafen 12, D-27570 Bremerhaven, Germany \\ ${ }^{2}$ Institute for Plant Biochemistry, University of Tübingen, Corrensstrasse 41, D-72076 Tübingen, Germany \\ ${ }^{3}$ Max Planck Institute for Marine Microbiology, Celsiusstrasse 1, D-28359 Bremen, Germany
}

\begin{abstract}
Biomass and the concentrations of the UV-absorbing compounds scytonemin, pterins and mycosporine-like amino acid compounds (MAAs) were determined in a seasonal study of a cyanobacterial mat growing on an intertidal mangrove sediment at Towra Point, Sydney, Australia. The community was dominated by the filamentous cyanobacteria Lyngbya cf. aestuarii and Microcoleus chthonoplastes. While the first occurred as a thin compact layer on top of the mat without any obvious indication of growth over the course of the study, the latter formed a layer underneath Lyngbya and showed an increase in the thickness of the layer after the summer period. The sheath pigment scytonemin was only formed by $L$. cf. aestuarii and represented at all sampling dates the quantitatively most important UV-absorbing compound, ranging from 140 to $1300 \mathrm{mg} \mathrm{m}^{-2}$. The areal scytonemin content seemed to follow the seasonally fluctuating solar intensity. In contrast, the areal contents of pterins and MAAs did not increase under elevated solar radiation conditions. The data indicate the importance and effectiveness of scytonemin deposition in the outer sheaths of $L$. cf. aestuarii as a sunscreen for the entire benthic community underneath.
\end{abstract}

KEY WORDS: Cyanobacteria - Lyngbya cf. aestuarij - Microcoleus chthonoplastes Mycosporine-like amino acid compounds - Pterins - Seasonality - Scytonemin - UV radiation - UV sunscreen

\section{INTRODUCTION}

Cyanobacterial mats often develop on salt marsh and mangrove intertidal flats in warm-temperate to tropical regions, where they play an important role as primary producers, as well as in the formation, stabilization and biogeochemistry of sediments (Hussain \& Khoja 1993, Paterson 1994, Pinckney et al. 1995). In these habitats, microbial mats experience tidal immersion-emersion cycles and, under such conditions, they are subjected to strong amplitudes in salinity and irradiance, as well as long intervals of desiccation (Potts 1994, Bebout \& Garcia-Pichel 1995, Karsten 1996). Enhanced solar ultraviolet (UV) radiation due to the depletion of the stratospheric ozone layer has been proposed as a major stress factor for many photo-

•E-mail: ukarsten@awi-bremerhaven.de trophic organisms in aquatic ecosystems (Franklin \& Forster 1997). In warm-temperate to tropical regions the UV radiation is strong enough to affect marine organisms in the intertidal zone even under normal stratospheric ozone concentrations (Fleischmann 1989 Madronich 1993).

Deleterious effects of UV radiation on marine primary producers are well recognised, and include the direct effects of UV-B (280 to $320 \mathrm{~nm}$ ) on molecular targets such as DNA, RNA and proteins, on physiological processes such as photosynthesis and on community structures (Smith et al. 1992, Buma et al. 1995, Davidson et al. 1996, Franklin \& Forster 1997). Although UV-A (320 to $400 \mathrm{~nm}$ ) may also have a net damaging influence on photosynthesis (Cullen et al. 1992), this waveband in general exerts a more positive effect on physiology by inducing photobiological events such as photolyase activity for DNA damage (Buma et al. 
1997). Of major interest is the identification of repair and/or protective mechanisms that allow phototrophic organisms living in high-light habitats to survive and reproduce.

Besides the migration of filamentous cyanobacteria in microbial mats as a mechanism to avoid excessive exposure to harmful UV-B radiation (Bebout \& GarciaPichel 1995), many species have been shown to produce various types of UV-absorbing compounds (Garcia-Pichel \& Castenholz 1993). Three chemical classes of these substances have been identified in cyanobacteria: the brown pigment scytonemin, an indole alkaloid located in the extracellular sheath with an absorption maximum in the UV-A range $(370 \mathrm{~nm}$ in vivo) (Garcia-Pichel \& Castenholz 1991), as well as mycosporine-like amino acid compounds (MAAs) (GarciaPichel \& Castenholz 1993, Böhm et al. 1995, Karsten \& Garcia-Pichel 1996) and pterins (Matsunaga et al. 1993), which optimally absorb at shorter wavelengths between 310 and $360 \mathrm{~nm}$. The physiological function of scytonemin as an effective UV sunscreen has conclusively been shown in different strains of cyanobacteria isolated from sun-exposed habitats (Garcia-Pichel \& Castenholz 1991, Garcia-Pichel et al. 1992, Brenowitz \& Castenholz 1997). In contrast to scytonemin, MAAs represent a suite of chemically related water-soluble compounds which are in most cases intracellularly located. In the terrestrial cyanobacterium Gloeocapsa sp. the MAA concentrations were a function of the UV$B$ dose (Garcia-Pichel et al. 1993), and the estimation of their sunscreen capacities suggested a significant protection from potentially deleterious UV effects (GarciaPichel \& Castenholz 1993). A possible role of pterins as UV-protecting compounds has recently been suggested for the marine planktonic cyanobacterium

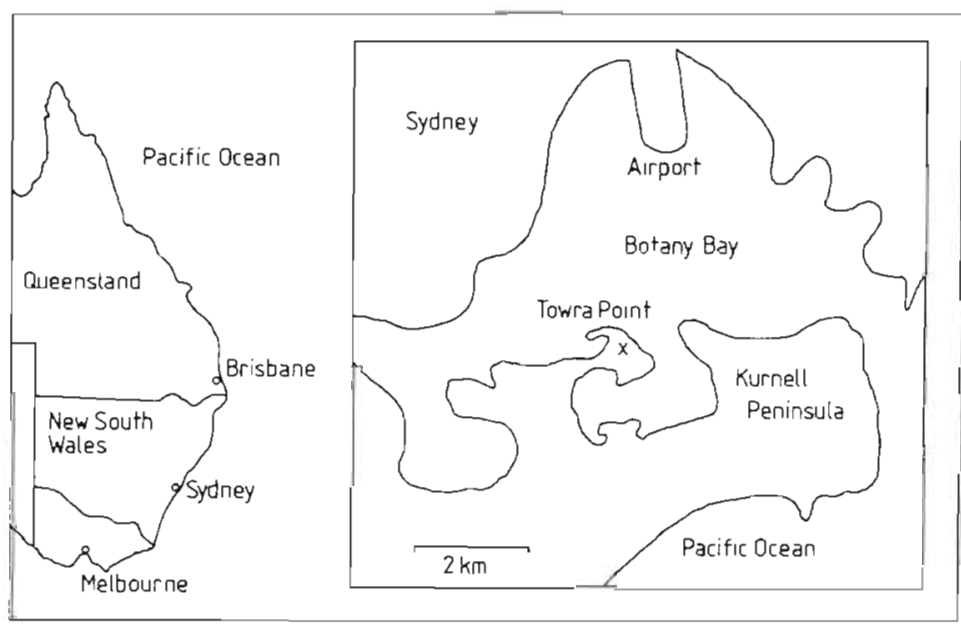

Fig. 1 Map of the location Towra Point, Sydney, Australia where the intertidal cyanobacterial mats were collected between July 1995 and May 1996
Oscillatoria sp. since UV-A radiation has been reported to be very effective in eliciting biosynthesis of a biopterin glucoside compound (Matsunaga et al. 1993). However, the metabolic function of pterins in various phototrophic organisms is not understood (Galland \& Senger 1988), and the average amounts of pterins accumulated by cyanobacteria do not attain concentrations high enough to provide a significant optical effect (Grether et al. 1996).

The possible seasonal variation in the concentration of UV-absorbing compounds in natural microbial communities has never been investigated, neither under simulated laboratory conditions nor in the field. Therefore, the objective of this study was to determine over a period of $1 \mathrm{yr}$ the contents of all scytonemin, MAAs and pterins in a cyanobacterial mat growing on an intertidal mangrove sediment under natural insolation. Of special interest was the evaluation of the type of compound which may be the most important as UV sunscreen in the field, and to understand speciesspecific acclimation strategies in various members of the mat under elevated solar radiation in summer.

\section{MATERIALS AND METHODS}

Microbial mats were collected from an intertidal mangrove sandy sediment at Towra Point, a small peninsula located at the southern shore of Botany Bay, Sydney, Australia (Fig. 1). Sampling of ca $30 \times 30 \mathrm{~mm}$ pieces, $10 \mathrm{~mm}$ deep, was done between July 1995 and May 1996 in intervals of 2 wk. After collection mat samples were kept in the dark and air-dried in the laboratory overnight. They were stored in the dark in a refrigerator at $4^{\circ} \mathrm{C}$ in sealed plastic bags until chemical analysis, which took place within $8 \mathrm{wk}$ after sampling. Under these conditions no substantial degradation of chlorophyll a (chl a) as indicated by the presence of phaeophytin a or chlorophyllide a could be observed.

Data on air temperature and rainfall were collected from the meteorological station at Sydney Airport, information on water temperature was kindly provided by Dr I. Suthers (University of New South Wales, Sydney), data on UV radiation were obtained from the Australian Radiation Laboratory in Melbourne, and sunrise and sunset times for the calculation of daylengths were obtained from Sydney Observatory. The values for maximum and minimum air temperature and for water temperature represent the average temperature of $2 \mathrm{wk}$ before each sampling date. For the daily UV-B doses (280 to $320 \mathrm{~nm}$ ) the average of $3 \mathrm{~d}$ before each sampling was calculated. 
Nomarski interference contrast microscopy and epifluorescence microscopy were done with a Zeiss Axioplan microscope to examine the presence and distribution of cyanobacterial species in the microbial mat during the course of the seasons. The percentage cover at the surface of the mat and in $<1 \mathrm{~mm}$ depth was estimated for the most abundant filamentous species Lyngbya cf. aestuarii Liebm. and Microcoleus chthonoplastes Thuret in ca $200 \mu \mathrm{m}$ thin sections sliced from the cores by using a razor blade. The respective thin sections were microscopically investigated by counting the percentage cover of the bottom area of randomly selected fields. 'L. aestuarii' is a common morphotype in mats, but its taxonomic validity has not been studied with modern methods. Therefore we use L. cf. aestuarii (cum forme).

For the determination of the various UV-absorbing compounds, air-dried field samples were remoistened with several drops of sterile seawater. Afterwards 3 or 4 independent mini-cores (inner diameter of $8 \mathrm{~mm}$ ) were taken with the thick end of a Pasteur pipette. The uppermost cyanobacterial mat layer had a maximum thickness of ca $2 \mathrm{~mm}$. The biomass of each core was determined using chl a concentration as indicator. This pigment was extracted together with the sheath pigment scytonemin in ice-cold $100 \%$ acetone and analysed by HPLC as described in detail by Karsten \& Garcia-Pichel (1996). Scytonemin and chl a showed retention times of 2.05 and $15.80 \mathrm{~min}$, respectively, and were identified by co-chromatography with authentic scytonemin isolated from a pure culture of the wellcharacterised cyanobacterium Scytonema javanicum strain B-77 (Garcia-Pichel \& Castenholz 1991) and by using a commercially available chl a standard (Sigma Chemical Co.j. Pigments were quantified by peak areas using molar extinction coefficients for scytonemin and chl $a$ of 27.9 and 91.7 at $436 \mathrm{~nm}$, respectively. Mini-cores were also directly extracted for quantitative MAA determination. Sample extraction and HPLC analysis were carried out according to Karsten \& Garcia-Pichel (1996) modified as follows. MAAs were separated on a stainless-steel Knauer Spherisorb RP-8 column ( $5 \mu \mathrm{m}, 250 \times 4 \mathrm{~mm}$ I.D.) protected with a RP-8 guard cartridge $(20 \times 4 \mathrm{~mm}$ I.D. $)$. The mobile phase was $25 \%$ aqueous methanol (v/v) plus $0.1 \%$ acetic acid $(\mathrm{v} / \mathrm{v})$ in water. This solvent was isocratically run at a flow rate of $0.7 \mathrm{ml} \mathrm{min}^{-1}$. MAAs were detected at $335 \mathrm{~nm}$ and absorption spectra were recorded each second between 290 and 400 nm directly on the HPLCseparated peaks. Identification was made by spectra, retention time and in some cases co-chromatography with standards extracted from the marine organisms Lissoclinum patella (ascidean), Palythoa tuberculosa (zoanthid), coral trout lenses and the red macroalga Porphyra sp., which were kindly provided by Dr D.
Karentz (Department of Biology, University of San Francisco, USA). While some MAAs such as shinorine were easily identified, most others remained unknown. Therefore the sum of all compounds was summarized and quantified by using an average extinction coefficient of $120 \mathrm{l} \mathrm{g}^{-1} \mathrm{~cm}^{-1}$ (Garcia-Pichel \& Castenholz 1993), as well as an average molecular weight of 300.

Pterins were extracted in $\mathrm{HCl}$, oxidized to their fluorescent forms with iodine, purified by cation-exchange chromatography and separated using reverse-phase HPLC with fluorescence detection. The methodology for pterin isolation, analysis, identification and quantification is described in detail by Maier \& Ninnemann (1995).

The concentrations of chl $a$ and the various UVabsorbing compounds are expressed in units of mass per surface area of mat.

\section{RESULTS}

Botany Bay is an estuary with many small peninsulas, inlets and tidal channels whose shores are covered with mangrove and salt marsh vegetation, as well as with microbial mats on the tidal flats. The salinity in the water column at Towra Point, a small peninsula (Fig. 1), fluctuates usually between 25 and 34 ppt, with lower values after heavy rainfalls or freshwater run-off, and higher values after long periods of evaporation especially in summer. The seasonal soil salinity fluctuates between 12 and 78 ppt (calculated from Clarke \& Hannon 1969). At this location water and air temperatures increased starting in August (water: $13.9^{\circ} \mathrm{C}$; air: $16.3^{\circ} \mathrm{C}$ ), and the maximum was measured in January (water: $22.6^{\circ} \mathrm{C}$; air: $26.6^{\circ} \mathrm{C}$ ) (Fig. 2), indicating relatively small annual differences. Calculations of the seasonal change in daylength gave a minimum of $9.9 \mathrm{~h}$ in late June and a maximum of $14.4 \mathrm{~h}$ in late December (Fig. 2). Comparisions between the daily total UV-B doses clearly showed a $>5$-fold increase from the beginning of the study in July until December/January followed by a gradual decrease back to the original level in mid May (Fig. 2).

The type of microbial mat studied consisted of 2 distinct layers growing always fully exposed to solar radiation on top of a sandy sediment (Fig. 3). While the top layer had a nearly constant thickness in the range of $0.5 \mathrm{~mm}$ and a brownish colour over the course of the seasons, the underlying lamina varied between 0.7 and $1.5 \mathrm{~mm}$ in thickness and appeared always blue-green coloured. This blue-green layer was generally thicker in the second period of this study after the summer, compared to the first 6 mo. Microscopical examinations demonstrated the dominant occurrence of the filamentous cyanobacterium Lyngbya cf, aestuarii at the sur- 


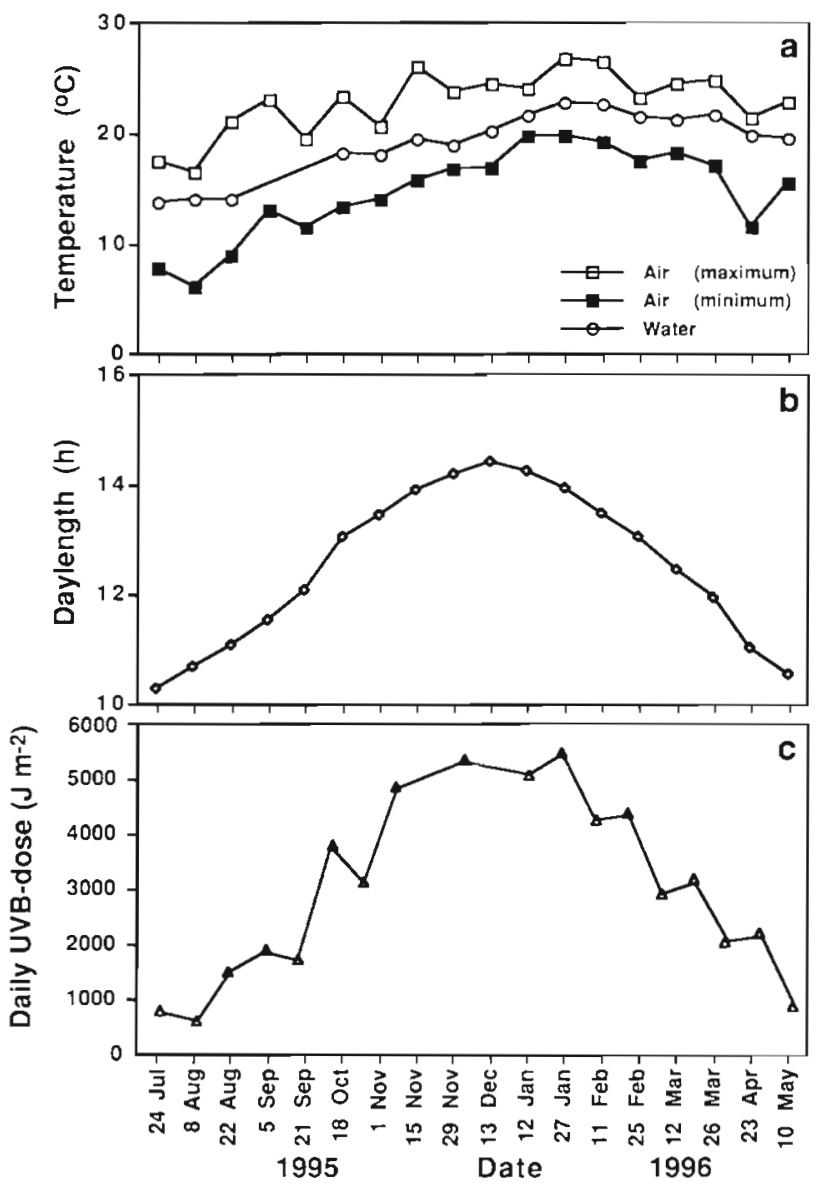

Fig. 2. Seasonal changes in environmental conditions at Towra Point, Sydney, Australia between July 1995 and May 1996. (a) Maximum and minimum air temperature, and water temperature; values represent average temperature of the 2 wk period before each sampling date. (b) Daylength calculated from sunrise until sunset. (c) Daily UV-B dose (280 to $320 \mathrm{~nm}$ ); values represent average of $3 \mathrm{~d}$ before each sampling date
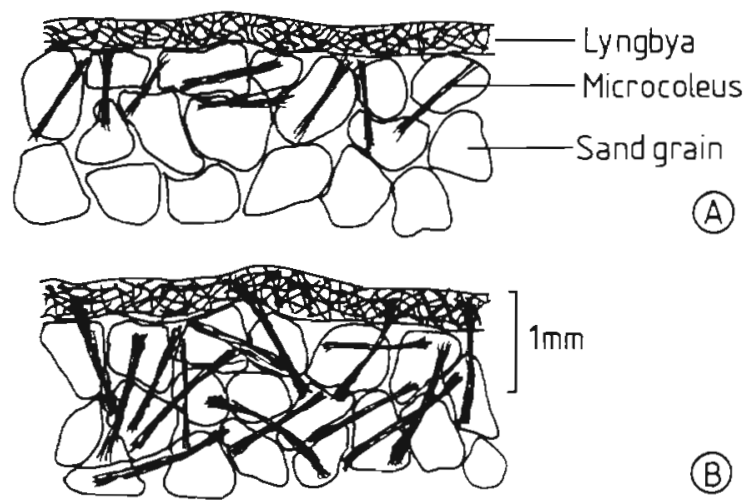

Fig. 3. Seasonal aspects of 2 cross-sections through the cyanobacterial mat studied, showing (A) summer (13 December 1995 ) and (B) late autumn samples (10 May 1996)
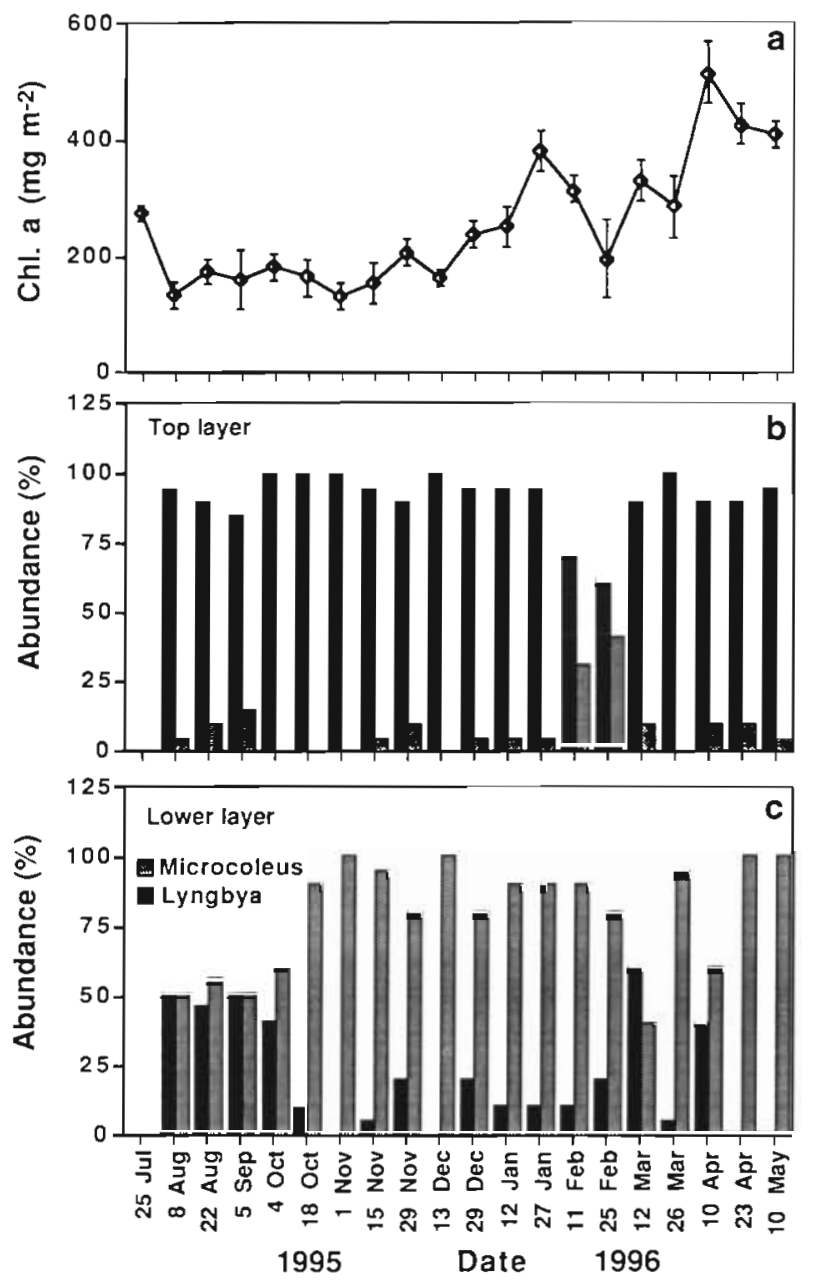

Fig. 4. Seasonal changes in (a) total cyanobacterial biomass expressed as areal chlorophyll a (chl a) concentration (mean value $\pm S D, n=4$ ), and percentage abundance of Lyngbya cf. aestuarii and Microcoleus chthonoplastes (b) at the mat surface and (c) in $1 \mathrm{~mm}$ depth

face of the mat (Fig. 4). This species contains large amounts of the brown pigment scytonemin, which characteristically tints their extracellular sheaths (Garcia-Pichel \& Castenholz 1991). The blue-green layer was dominated by another filamentous cyanobacterium, Microcoleus chthonoplastes, which could be seen in $0.2 \mathrm{~mm}$ thin sections sliced from $1 \mathrm{~mm}$ depth (Fig. 4). While $L$. cf. aestuarii was always the quantitatively dominant species in the uppermost surface area over the course of the seasons, some variation in the distribution of both species was determined in the deeper parts of the mat. Although both species represented at all sampling dates more than $98 \%$ of the cyanobacterial biomass, in some samples very sparsely distributed colonies of other species such as Phormidium sp. and Aphanothece sp. (= Cyanothece sp.) were also observed. 


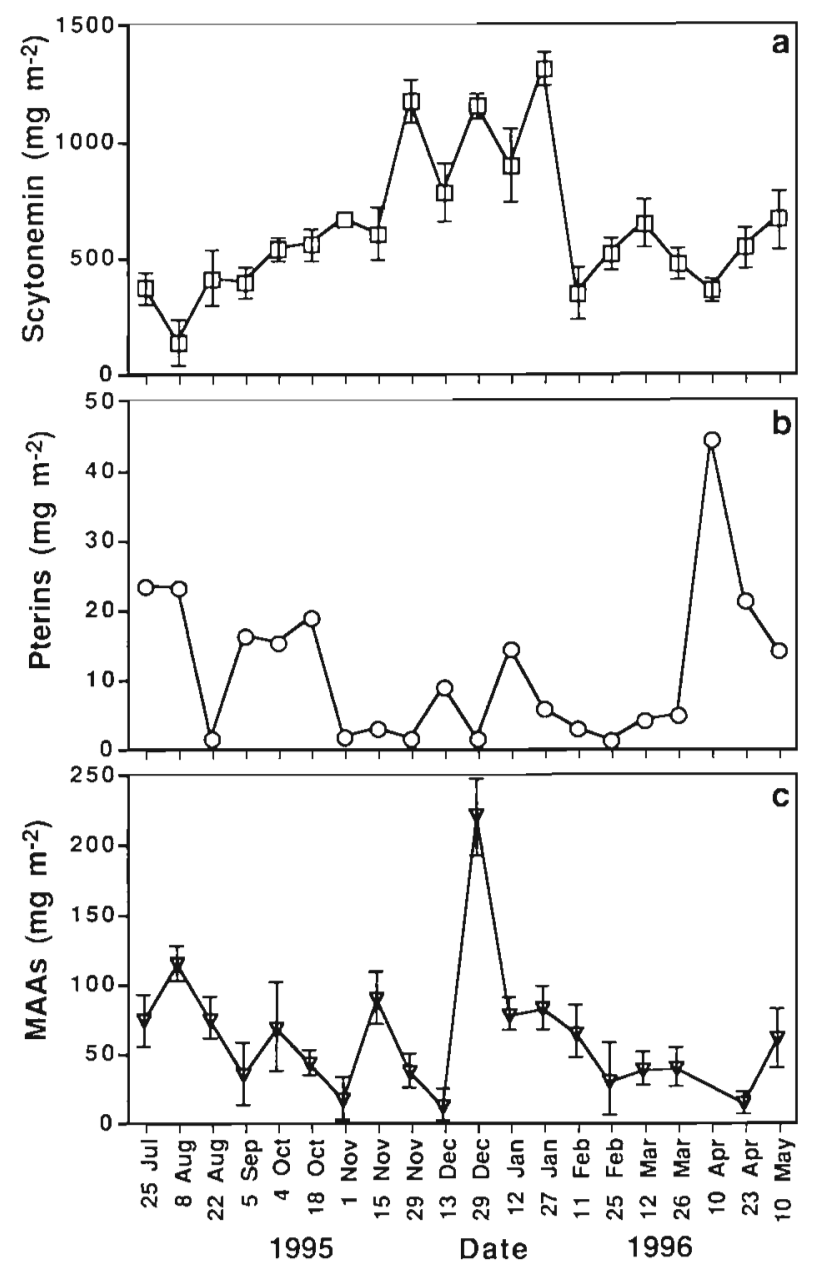

Fig. 5. Seasonal changes in the concentrations of the UVabsorbing compounds (a) scytonemin, (b) pterins and (c) mycosporine-like amino acid compounds (MAAs) extracted from the cyanobacterial community. While the given amounts of scytonemin and MAAs represent mean values ( $\pm \mathrm{SD}$ ) of 4 replicates, the shown pterin contents were each determined from 1 mat piece only

$\mathrm{Chl} a$ as an indicator of total oxygenic phototroph biomass remained constant at 130 to $160 \mathrm{mg} \mathrm{chl} \mathrm{a} \mathrm{\textrm {m } ^ { - 2 }}$ surface area from the beginning of the study until mid December, followed by a more than 2 -fold increase over the summer and autumn up to $>400 \mathrm{mg} \mathrm{chl} \mathrm{a} \mathrm{\textrm {m } ^ { - 2 }}$ in mid May (Fig. 4). The concentration of phaeophytin $a_{l}$ an indicator of degrading cells, was always less than $3 \%$ of the chl a value (data not shown). This biomass increase correlated with an increase in thickness of the Microcoleus layer in the mat.

The seasonal variation of the 3 classes of UV-absorbing compounds extracted and analysed from the microbial mat indicated different concentration ranges for each group (Fig. 5). While the sheath pigment scytonemin always showed high areal values ranging from 140 to $1300 \mathrm{mg} \mathrm{m}^{-2}$, the amounts of pterins and
MAAs varied from 1 to 44 and 10 to $218 \mathrm{mg} \mathrm{m}^{-2}$ respectively, over the course of the seasons. The scytonemin concentration gradually rose from $400 \mathrm{mg} \mathrm{m}^{-2}$ at the beginning of the study to $550 \mathrm{mg} \mathrm{m}^{-2}$ in mid November, followed by a strong and significant increase up to $1300 \mathrm{mg} \mathrm{m}^{-2}$ over the summer months $(p<0.01$, 1-way ANOVA) (Fig. 5). Between late January and mid February a sharp decline in scytonemin content down to $350 \mathrm{mg} \mathrm{m}^{-2}$ was observed, followed by a fluctuating value ranging from 350 to $610 \mathrm{mg} \mathrm{m}^{-2}$ until the end of the study. While scytonemin exhibited highest values in December and January, the sum of pterins was lowest at this time up until mid March (Fig. 5). From the beginning of the study until mid October, and from mid April until mid May, the pterin concentrations were generally 3 - to 4 -fold higher compared with the lower summer/autumn values. The MAA contents showed a very high amount of $218 \mathrm{mg}$ $\mathrm{m}^{-2}$ only in late December (Fig. 5). At all other sampling dates, fluctuating concentrations were determined ranging from 10 to $120 \mathrm{mg} \mathrm{m}^{-2}$ which were randomly distributed over the course of the seasons. MAA samples were always quantitatively dominated by a compound with an absorption maximum at $332 \mathrm{~nm}$ assigned as MAA No. 3 according to Karsten \& GarciaPichel (1996). In some mini-cores minor concentrations of shinorine were also present (data not shown).

The molar ratios for each of the UV-absorbing compounds and chl a were used to infer changes in the accumulation of these substances with biomass (Fig. 6). An increase in these ratios indicates an increase in UV-absorbing compounds relative to total biomass and vice versa. The scytonemin/chl a ratio strongly rose from 2.4 at the beginning of the study up to 9.5 in late November followed by a gradual decrease until mid May back to the first value. In contrast, the pterin/chl a and MAA/chl a ratios fluctuated much more randomly over the course of the seasons (Fig. 6).

\section{DISCUSSION}

The chl a concentrations in the microbial mat studied seasonally varied between 130 and $500 \mathrm{mg} \mathrm{m}^{-2}$ which is in good agreement with values of other cyanobacterial communities from mangrove locations (Sournia 1977. Potts 1980). Potts (1980) estimated for various types of standing crop chl a contents between 59 and $436 \mathrm{mg}$ $\mathrm{m}^{-2}$ (recalculated from his Table 3), while Sournia (1977) reported amounts in the range 100 to $200 \mathrm{mg}$ $\mathrm{m}^{-2}$. However, none of these studies took any account of seasonality. A recent investigation of a similar type of cyanobacterial mat from a sandy tidal flat in North Carolina, USA, clearly indicated a strong impact of seasonality on community composition, chl a concentration 

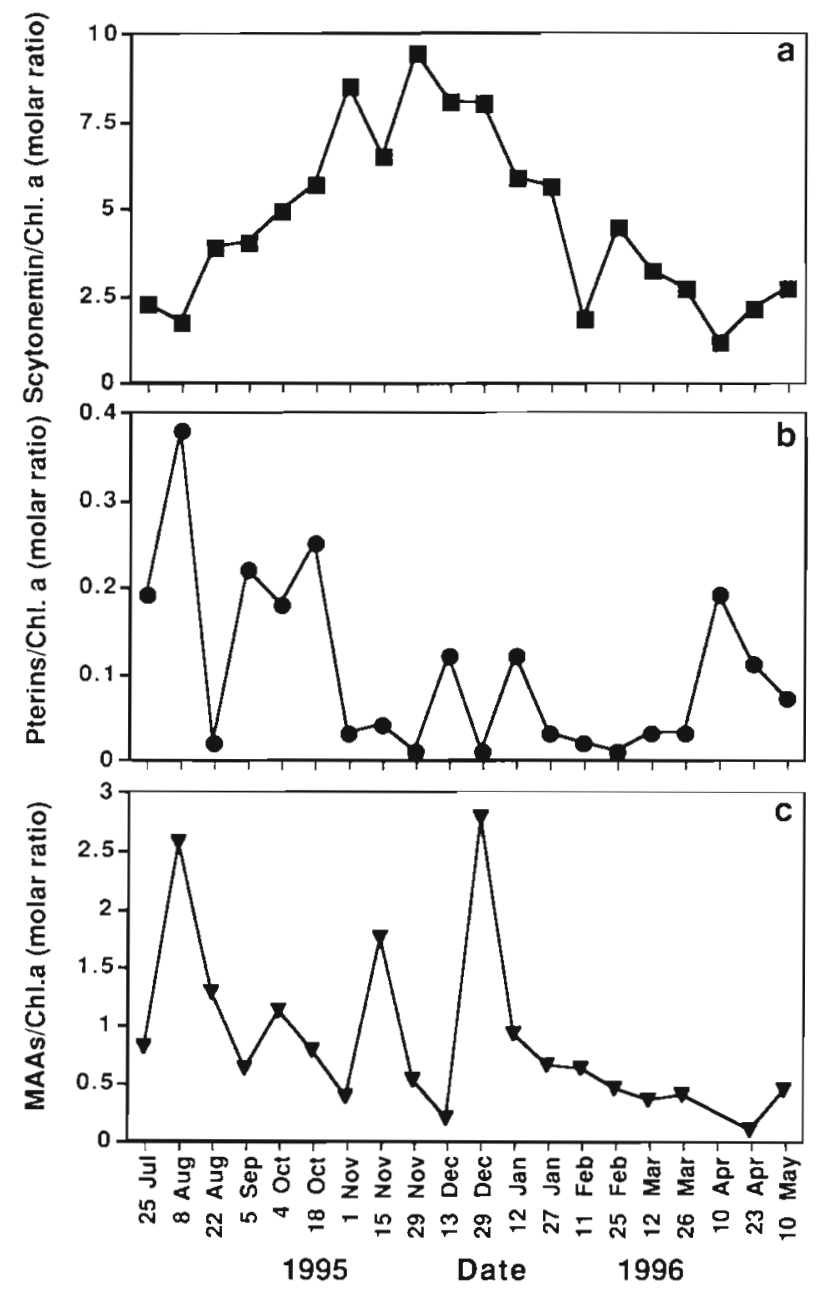

Fig. 6. Seasonal changes in the molar ratios of (a) scytonemin, (b) pterins and (c) mycosporine-like amino acid compounds (MAAs) to chl $a$ in the cyanobacterial community

and nitrogen fixation (Pinckney et al. 1995). Mat biomass generally increased over the summer period. In contrast to the investigation of Pinckney et al. (1995), chl a concentration of the mangrove mat studied here rose from the end of the summer until late autumn (Fig. 4). This suggests that biomass accretion occurred which is well reflected in the cyanobacterial layer underneath the surface that became thicker and more dense over time. The most abundant species in this part of the system was Microcoleus chthonoplastes, a cosmopolitan member of many marine microbial mats from temperate to tropical regions (Prufert-Bebout \& GarciaPichel 1994). In many such mats, the cyanobacterial layer is formed almost exclusively by this species.

In contrast to Microcoleus chthonoplastes, biomass of Lyngbya cf. aestuarii at the mat surface seemed more or less constant over the course of the seasons since no obvious increase in cell density or in the thickness of this layer could be observed. However, the strong formation and accumulation of scytonemin over the summer period clearly indicates physiological activity of this species. $L$. cf. aestuarii has seemingly also a worldwide distribution, and is known as well to form fabric-like mats in intertidal and shallow marine habitats (Castenholz \& Waterbury 1989).

The data presented clearly indicate that in terms of quantity scytonemin was the most important UVabsorbing substance of the microbial community. The areal scytonemin concentrations varied nearly 10 -fold between 140 and $1300 \mathrm{mg} \mathrm{m}^{-2}$ over the course of the seasons (Fig. 5). Values as high as $1300 \mathrm{mg} \mathrm{m}^{-2}$ have never been reported before, although desert lightexposed soil crusts which are formed by various cyanobacterial species have been shown to contain 1.8 to $335 \mathrm{mg}$ scytonemin $\mathrm{m}^{-2}$ (Garcia-Pichel \& Belnap 1996). This pigment is apparently restricted to cyanobacteria, and it has been isolated and identified from more than 30 sheathed species, as well as from cyanobacterial lichens, all of which were collected from high-light habitats (Proteau et al. 1993, Büdel et al. 1997). However, in a recent study a UV-absorbing compound with physico-chemical properties similar to those of scytonemin was reported for the first time in phytoplankton samples collected in the North Atlantic (Llewellyn \& Mantoura 1997). In the terrestrial cyanobacterium Chlorogloeopsis $\mathrm{sp}$., it has been reported that UV-A exposure induced photoinhibition and growth delay until substantial concentrations of scytonemin had been synthesized and deposited in the extracellular envelopes (Garcia-Pichel et al. 1992). In natural Calothrix sp. biofilms a correlation between scytonemin level and resistance of photosynthesis under UV exposure has been demonstrated (Brenowitz \& Castenholz 1997). Other data indicate a strong stimulating effect of increasing PAR and UV-A doses on the accumulation of this compound in various cyanobacterial species (Garcia-Pichel et al. 1991). The latter authors also demonstrated that scytonemin formation was a physiological process and not due to a mere photochemical conversion of a precursor under high irradiance. Although we could not distinguish between specific spectral effects on the UVabsorbing compounds in the cyanobacterial community, i.e. whether PAR, UV-A or UV-B is mainly responsible for inducing the synthesis and accumulation of scytonemin, it is obvious that the seasonal scytonemin/chl a ratio (Fig. 6) follows well the annual fluctuations in solar intensity. This fluctuation is reflected by daylength and UV-B dose (Fig. 2), as well as by PAR and UV-A for which we were unable to obtain data.

Radiation measurements inside a cyanobacterial lichen by using a microprobe showed a strong attenuation of UV-A/B in the outer parts of the thallus due to 
the presence of high concentrations of scytonemin (Büdel et al. 1997). These data clearly indicate the effectiveness of this compound as a UV sunscreen. Therefore, it seems that under natural conditions increasing UV radiation stimulates the synthesis and accumulation of high scytonemin concentrations in the top Lyngbya layer. As a consequence, the presence of this compound protects this species against incoming UV radiation, as well as all other members of the benthic community underneath.

While scytonemin in this community is restricted to Lyngbya cf. aestuarii, MAAs occur in both cyanobacterial species as determined for pure cultures (data not shown). Moreover, while scytonemin is extracellularly deposited and an environmentally quite stable compound, MAAs are most often intracellularly located. The MAA concentrations of the microbial mat were randomly scattered over the course of the seasons without any obvious trend. The amounts determined in this study suggest some protective role as a passive UV sunscreen. However, since the scytonemin contents were always at least 1 order of magnitude higher than the MAAs, only an incomplete or limited protection against UV photodamage can be expected from the latter compounds. The same seems to be true for the presence of pterins, for which concentrations were 5to 10 -fold lower than those of the MAAs and, hence, a photoprotective role as sunscreen for the microbial mat can be ruled out. Moreover, while the highest scytonemin concentrations in the natural community were found under the highest ambient solar intensities, the variable amounts of MAAs and pterins over the course of the season indicate that the contents of these substances were not determined by exposure to increased radiation conditions.

In conclusion, in this field study we have shown that Lyngbya cf. aestuarii forms and accumulates very high concentrations of the UV sunscreen scytonemin in the top surface layer of the mat in parallel with seasonally fluctuating solar radiation. Microcoleus chthonoplastes, as well as all other microorganisms living underneath, would surely benefit from this dense scytonemin layer, which functions as a highly efficient UV sunscreen. Well protected from this harmful radiation, the shadeadapted $M$. chthonoplastes (Bebout \& Garcia-Pichel 1995) can grow and survive under the environmentally extreme conditions of the mangrove habitat.

Acknowledgements. Ulf Karsten thanks the European Community (Project ENV4-CT96-0188 [DG 12] - UV/marine macrophytes) for financial support. The authors thank Lani Barbieri, David Nicolls, Xiaomei Niu and Andrea Pillmann for technical help in the field, as well as Thomas Sawall for running the MAA analysis. This is publication No. 1427 of the Alfred Wegener Institute for Polar and Marine Research, Bremerhaven.

\section{LITERATURE CITED}

Bebout BM, Garcia-Pichel F (1995) UV B-induced vertical migrations of cyanobacteria in a microbial mat. Appl Environ Microbiol 61:4215-4222

Böhm GA, Pfleiderer W, Böger P, Scherer S (1995) Structure of a novel oligosaccharide-mycosporine-amino acid ultraviolet $\mathrm{A} / \mathrm{B}$ sunscreen pigment from the terrestrial cyanobacterium Nostoc commune. J Biol Chem 270:8536-8539

Brenowitz S, Castenholz RW (1997) Long-term effects of UV and visible irradiance on natural populations of a scytonemin-containing cyanobacterium (Calothrix sp.). FEMS Microbiol Ecol 24:343-352

Büdel B, Karsten U, Garcia-Pichel F (1997) UV-absorbing scytonemin and mycosporine-like amino acid derivatives in exposed, rock-inhabiting cyanobacterial lichens. Oecologia 112:165-172

Buma AGJ, Engelen AH, Gieskes WWC (1997) Wavelengthdependent induction of thymine dimers and growth rate reduction in the marine diatom Cyclotella sp. exposed to ultraviolet radiation. Mar Ecol Prog Ser 153:91-97

Buma AGJ, Van Hannen EJ, Roza L, Veldhuis MJW, Gieskes WWC (1995) Monitoring ultraviolet-B-induced DNA damage in individual diatom cels by immunofluorescent thymine dimer detection. J Phycol 31:314-321

Castenholz RW, Waterbury JB (1989) Oxygenic photosynthetic bacteria. In: Staley JT, Bryant MP, Pfennig N, Holt JG (eds) Bergey's manual of systematic bacteriology, Vol 3. Williams and Wilkins, Baltimore, p 1710-1799

Clarke LD, Hannon NJ (1969) The mangrove swamp and salt marsh communities of the Sydney district. J Ecol 57: 213-234

Cullen JJ, Neale PJ, Lesser MP (1992) Biological weighting function for the inhibition of phytoplankton photosynthesis by ultraviolet radiation. Science 258:646-650

Davidson AT, Marchant HJ, de la Mare WK (1996) Natural UV-B exposure changes the species composition of Antarctic phytoplankton in mixed culture. Aquat Microb Ecol 10:299-305

Fleischmann EM (1989) The measurement and penetration of ultraviolet radiation into tropical marine water Limnol Oceanogr 34:1623-1629

Franklin LA, Forster R (1997) The changing irradiance environment: consequences for marine macrophyte physiology, productivity and ecology. Eur J Phycol 32:207-32

Galland P, Senger H (1988) The role of pterins in the photoreception and metabolism of plants. Photochem Photobiol 48:811-820

Garcia-Pichel F, Belnap J (1996) Microenvironments and microscale productivity of cyanobacterial desert crusts. J Phycol 32:774-782

Garcia-Pichel F, Castenholz RW (1991) Characterization and biological implications of scytonemin, a cyanobacterial sheath pigment. J Phycol 27:495-409

Garcia-Pichel F, Castenholz RW (1993) Occurrence of UVabsorbing, mycosporine-like compounds among cyanobacterial isolates and an estimate of their screening capacity. Appl Environ Microbiol 59:163-169

Garcia-Pichel F, Sherry ND, Castenholz RW (1992) Evidence for an ultraviolet sunscreen role of the extracellular pigment scytonemin in the terrestrial cyanobacterium Chlorogloeopsis sp. Photochem Photobiol 56:17-23

Garcia-Pichel F, Wingard CE, Castenholz RW (1993) Evidence regarding the UV sunscreen role of a mycosporinelike compound in the cyanobacterium Gloeocapsa sp. Appl Environ Microbiol 59:170-176

Grether T, Maier J, Karsten U, Garcia-Pichel F, Ninnemann H 
(1996) UV-light induction of biosynthesis of pteridine glycosides in cyanobacteria. In: Abstract book of the 12th International Congress on Photobiology, 1-6 September 96. Vienna, Austria

Hussain MI Khoja TM (1993) Intertidal and subtidal bluegreen algal mats of open and mangrove areas in the Farasan Archipelago (Saudi Arabia), Red Sea. Botanica Mar 36:377-88

Karsten U (1996) Growth and organic osmolytes of geographically different isolates of Microcoleus chthonoplastes (cyanobacteria) from benthic microbial mats: response to salinity change. J Phycol 32:501-506

Karsten U, Garcia-Pichel F (1996) Carotenoids and mycosporine-like amino acid compounds in members of the genus Microcoleus (Cyanobacteria): a chemosystematic study. Syst Appl Microbiol 19:285-294

Llewellyn CA, Mantoura RFC (1997) A UV absorbing compound in HPLC pigment chromatograms obtained from Icelandic Basin phytoplankton. Mar Ecol Prog Ser 158: 283-287

Madronich S (1993) The atmosphere and UV-B radiation at ground level. In: Young AR, Björn LO, Moan J, Nultsch W (eds) Environmental UV photobiology. Plenum Press, New York, p 1-40

Maier J, Ninnemann H (1995) Biosynthesis of pteridines in Neurospora crassa, Phycomyces blakesleeanus and Euglena gracilis: detection and characterization of biosynthetic enzymes. Photochem Photobiol 61:43-53

Matsunaga T, Burgess JG, Yamada N, Komatsu K, Yoshida S, Wachi Y (1993) An ultraviolet (UV-A) absorbing biopterin glucoside from the marine planktonic cyanobacterium

Editorial responsibility: William $L i$,

Dartmouth, NS, Canada
Oscillatoria sp. Appl Microbiol Biotechol 39:250-253

Paterson DM (1994) Microbial mediation of sediment structure and behaviour. In: Stal LJ, Caumette P (eds) Microbial mats, NATO ASI Series, Vol G 35. Springer-Verlag, Berlin, p 97-110

Pinckney J, Paerl HW. Fitzpatrick M (1995) Impacts of seasonality and nutrients on microbial mat community structure and function. Mar Ecol Prog Ser 123:207-216

Potts M (1980) Blue-green algae (Cyanobacteria) in marine coastal environments of the Sinai Peninsula; distribution, zonation, stratification and taxonomic diversity, Phycologia 19:60-73

Potts M (1994) Desiccation tolerance of prokaryotes. Microb Rev 58:755-805

Proteau PJ, Gerwick WH, Garcia-Pichel F, Castenholz RW (1993) The structure of scytonemin, an ultraviolet sunscreen pigment from the sheaths of cyanobacteria. Experientia 49:825-829

Prufert-Bebout L, Garcia-Pichel F (1994) Field and cultivated Microcoleus chthonoplastes: the search for clues to its prevalence in marine microbial mats. In: Stal LJ, Caumette P (eds) Microbial mats, NATO ASI Series, Vol G 35. Springer-Verlag, Berlin, p 111-6

Smith RC, Prezelin BB, Baker KS, Bidigare RR, Boucher NP, Coley T, Karentz D, MacIntyre S, Matlick HA, Menzies D, Ondrusek M, Wan Z, Waters KJ (1992) Ozone depletion: ultraviolet radiation and phytoplankton biology in Antarctic waters. Science 255:952-959

Sournia A (1977) Notes on the primary productivity of coastal waters in the Gulf of Elat (Red Sea). Int Rev Ges Hydrobiol $62: 813-819$

Submitted: February 2, 1998; Accepted: May 18, 1998 Proofs received from author(s): August 14, 1998 